\title{
Application of Ventilation Technology of Bamboo Houses in Modern High-Rise Buildings
}

\author{
Zijie Zhou*, Yiqiang Xiao \\ School of Architecture, South China University of Technology, 381 Wushan Road, Tianhe District, Guangzhou 510640, \\ Guangdong Province, China. E-mail: 1811179614@qq.com
}

\begin{abstract}
The principle of L-shaped natural ventilation system of bamboo houses, traditional buildings in the hot-humid area of Lingnan, China, is now widely applied in the design of modern high-rise buildings. Taking the typical building case, the office building of Guangzhou Zhujiang Power Plant as an example, this article studies the natural ventilation system by the experimental method of combining actual measurement and simulation. It is concluded that the application benefits of the natural ventilation system in high-rise buildings can be improved by forming a complete ventilation path, increasing the area of air inlet and the distance between air inlet and air outlet.
\end{abstract}

Keywords: Bamboo House; Natural Ventilation; High-Rise Building; CFD Simulation

\section{Impact of climatic and geo- graphical conditions on architec- tural design}

Geographical and climatic conditions have great influence on the specific architectural design. Taking Lingnan area of China as an example, it is located in subtropical zone, with the main climatic characteristics of heat, humidity and rain. People may feel chest tightness when living in buildings. Coupled with the constant perspiration of the body, they will also suffer from wet and uncomfortable skin surface. To deal with such hot-humid climate, the solution is to ventilate the room and prevent the solar heat from entering the room as much as possible, so as to comprehensively cool the house $^{[1]}$.

Since ancient times, the design and construction of Lingnan buildings has been pursuing the seemingly contradictory elements of balanced ventilation, heat insulation and wind resistance. Architects devoted themselves to building buildings that can be ventilated, insulated and wind resistant. In the gradually formed traditional residential buildings in Lingnan style, there are numerous spatial features and structural details related to ventilation and wind resistance technology.

\section{Principle and technology of ven- tilation and cooling of bamboo houses-Lingnan tradition- al buildings}

\subsection{The basic principles of natural ventila- tion in buildings}

Natural ventilation in buildings, independent of equipment, has the following basic principles: 1) Ventilation with the help of wind pressure. The change of spatial scale leads to uneven air density and air pressure difference, thus forming air exchange between adjacent spaces. 2) Ventilation with the help of heat pressure. Due to the uneven air density caused by the change of temperature

Copyright (C) 2020 Zijie Zhou and Yiqiang Xiao

doi: 10.18282/adr.v2i2.1104

This is an open-access article distributed under the terms of the Creative Commons Attribution Non-Commercial License

(http://creativecommons.org/licenses/by-nc/4.0/), which permits unrestricted non-commercial use, distribution, and reproduction in any medium,

provided the original work is properly cited. 
difference, the exchange of cold and hot air can be formed, so as to achieve the purpose of ventilation. 3) Return air. The formation conditions of return air include keeping the wind field smooth, and at the same time, designing a shelter at an appropriate position inside the building, so as to enable the wind blown into the room through the air inlet to form a reverse flow.

\subsection{Brief introduction of ventilation tech- nology of bamboo houses}

Bamboo houses are not only provided with the universal ventilation technology in Lingnan area (including transom, windsail, screen door and grid door), but also develops a special natural ventilation system due to the limitation of extremely small ground area. It is impossible to form an air outlet because there are only patios and streets in front of the house, which is able to attract the wind into the room, while there is no spare space behind the house to build a backyard. Therefore, a vertical air outlet is formed by the patio, floor well or skylight in the building, forming an L-shaped ventilation path as a whole.

The ventilation mode of bamboo houses is: street alley-hall-cold alley-patio-outdoor ${ }^{[2]}$. It comprehensively applies wind pressure and heat pressure ventilation in the same system, thus realizing natural ventilation and cooling in buildings with narrow space.

\section{Application of ventilation princi- ple of bamboo houses in modern high-rise buildings}

\subsection{Problems faced by high-rise buildings in modern cities}

Comparing the traditional bamboo houses and their environment in Lingnan with the high-rise buildings and their environment in modern cities, it can be found that the latter are also faced with the same problems of limited land use and crowded space, which makes it difficult to form a complete natural ventilation system. The current situation is that high-rise buildings can only achieve indoor cooling with the help of some equipment like air conditioners in summer, which causes huge energy consumption.

\subsection{Strategies of natural ventilation for high-rise buildings in hot-humid areas}

The natural ventilation system of bamboo houses, with horizontal air inlet and vertical air outlet, is formed by comprehensive utilization of wind pressure and heat pressure ventilation, which can also be applied in high-rise buildings. In many high-rise buildings, the atrium space with open upper part and the side yard space are combined to form an L-shaped ventilation path similar to a bamboo house. Natural wind blows into the side yard from the street facing the building, and blows out from the top opening of the atrium. High-rise buildings with such spatial combinations include the main building of Shenzhen Institute of Building Research, the library building of Southern University of Science and Technology in Shenzhen, and the office building of Guangzhou Zhujiang Power Plant. However, there is no clear research result on the cooling benefit of this kind of ventilation system to the indoor space of buildings in summer.

\section{Experiment on natural ventila- tion effect of the office building of Guangzhou Zhujiang Power Plant}

\subsection{Purpose of the research}

To answer the question raised in the previous section, taking the office building of Guangzhou Zhujiang Power Plant as a typical case, this article conducts a quantitative study on the practical benefits of the application of L-shaped natural ventilation system in modern high-rise buildings through the methods of actual measurement and computer simulation. Besides, it also explores the influence of the specific combination of side yard and atrium on the cooling effect of natural ventilation.

\subsection{Case and design of working conditions}

There are 11 floors in the office building of Guangzhou Zhujiang Power Plant, in which there is a square atrium (6-11 floors) with a height of 6 floors in the inner center, and a side yard in the south, east and west respectively. This article focuses on natural ventilation system, without considering other space in the building except atrium and side yard, and detailed structures that have no influence on ventilation system. In order to simplify the experiment, only the atrium and the two side yards in the east and west are reserved. The size of the whole building is $47.4 \mathrm{~m} \times 33.75 \mathrm{~m} \times 33.75 \mathrm{~m}$; the size of the atrium 
is $25.2 \mathrm{~m} \times 20.25 \mathrm{~m} \times 20.25 \mathrm{~m}$; there is a circular corridor in each floor of the atrium with a width of $2.7 \mathrm{~m}$; there is a glass ceiling of $20.25 \mathrm{~m} \times 20.25 \mathrm{~m}$ just above the atrium roof at a height of $4.2 \mathrm{~m}$. The position, num- ber and size of the yards vary according to the experimental design. The specific design of the experimental working conditions is shown as Figure 1.

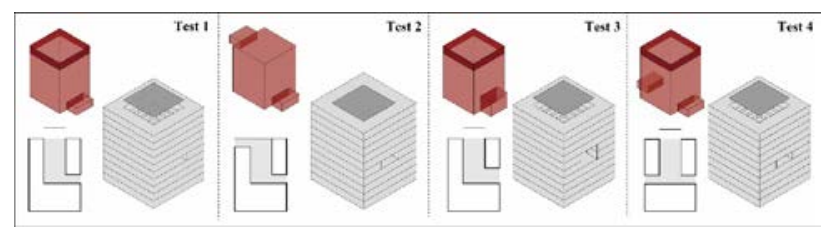

Figure 1. The design of experimental working conditions. (Source: drawn by the authors)

\subsection{Computer simulation and boundary condition setting}

The process of computer simulation is roughly as follows: CFD-Fluent is adopted to simulate the wind environment and thermal environment of the building, so as to obtain the wind speed and temperature data; the exterior surface temperature and mean radiant temperature (MRT) of the building are calculated by Honeybee in Ladybug Tools, and the physiological equivalent temperature (PET) can be calculated with the help of the wind speed and temperature data obtained by CFD-Fluent. PET represents the perceived comfort of an individual in a certain indoor setting, which can quantify the benefits of natural ventilation in buildings ${ }^{[3]}$.
This experiment was carried out on July 6th, 2020 and real data such as temperature and wind speed were measured in the office building of Guangzhou Zhujiang Power Plant. Then, the boundary conditions of computer simulation were set according to the data (as shown in Table 1). The influence of gradient wind effect ${ }^{[4]}$ on wind speed was paid special attention when simulating the wind field. Wind speed can be calculated as: $\mathrm{v}(\mathrm{z})=$ $\mathrm{v}(\mathrm{z} 0)(\mathrm{z} / \mathrm{z} 0) \mathrm{n}$, in which $\mathrm{v}(\mathrm{z})$ is the wind speed at a height of $\mathrm{z}$ from the ground, in $\mathrm{m} / \mathrm{s} ; \mathrm{v}(\mathrm{z} 0)$ is the wind speed at $10 \mathrm{~m}$ measured by the meteorological observatory, in $\mathrm{m} / \mathrm{s}$; $\mathrm{n}$ is the roughness index ${ }^{[5]}$, and $\mathrm{n}=0.4$ is taken for the central area of the city. The data each working condition is simulated and calculated until convergence.

Table 1. Boundary condition setting of the CFD-Fluent model

\begin{tabular}{|c|c|c|}
\hline Type & Projects & Main parameter \\
\hline \multirow{2}{*}{ Model } & Turbulence model & RNG k-e \\
\hline & Under relaxation factors & 0.7 \\
\hline Simulation time & 1 & June 20, 14:00 \\
\hline \multirow{3}{*}{ Geographical location } & City & Guangzhou \\
\hline & Time zone & $\mathrm{GMT}+8$ \\
\hline & Longitude; latitude & $113.27^{\circ} ; 23.13^{\circ}$ \\
\hline \multirow{3}{*}{$\begin{array}{l}\text { Meteorological pa- } \\
\text { rameters }\end{array}$} & Initial wind direction & $45^{\circ}(\mathrm{SE})$ \\
\hline & $\begin{array}{l}\text { Wind speed (the gradient wind is } 10 \\
\text { m away from the ground) }\end{array}$ & $2.5 \mathrm{~m} / \mathrm{s}$ \\
\hline & Initial air temperature & $30{ }^{\circ} \mathrm{C}$ \\
\hline \multirow{4}{*}{ Building material } & $\begin{array}{l}\text { Thickness, density, specific heat } \\
\text { and thermal conductivity of ground }\end{array}$ & $\begin{array}{l}10 \text { m; } 1600 \mathrm{Kg} / \mathrm{m}^{3} ; 300 \mathrm{j} / \mathrm{Kg}-\mathrm{k} ; 1.5 \\
\text { W/m-k }\end{array}$ \\
\hline & Thickness, density, specific heat & 0.3 m; 2000 Kg/m³; 900 j/Kg-k; 0.8 \\
\hline & and thermal conductivity of the wall & $\mathrm{W} / \mathrm{m}-\mathrm{k}$ \\
\hline & $\begin{array}{l}\text { Thickness, density, specific heat } \\
\text { and thermal conductivity of the } \\
\text { glass }\end{array}$ & $\begin{array}{l}0.05 \text { m; } 2200 \text { Kg/m³; } 830 \text { j/Kg-k; } 1.15 \\
\text { W/m-k }\end{array}$ \\
\hline
\end{tabular}




\subsection{Collection of result data}

The simulation result data of each working condition is collected by CFD-POST. The data such as coordinates, wind speed, wind direction and temperature of all points on the sections with atrium heights of $23.7 \mathrm{~m}$, $27.9 \mathrm{~m}, 32.1 \mathrm{~m}, 36.3 \mathrm{~m}, 40.5 \mathrm{~m}$ and $44.7 \mathrm{~m}$ (1.5 m above the ground level of each floor ${ }^{[6]}$ ) is collected. Draw the wind speed and temperature nephograms, and calculate the mean of each section.

\subsection{Analysis of the result}

\subsubsection{Analysis of simulation results of wind speed and temperature}

The atrium's mean wind speed of each section decreases with the increase of height. The wind speed in the corridor of each atrium section is generally lower than that in the center, indicating that the corridor can cut off the path of air flow upward from the bottom of the atrium, which can reduce the local wind speed. The mean wind speed at the bottom of the atrium is greater than that at other floors. And due to funnelling, the local wind speed facing the air inlet of the east side yard is obviously higher than that in the surrounding area. Except for the second working condition, airflow flows backward into the atrium at the top floor of other working conditions, leading to a slight increase in the atrium's mean wind speed of the section at the top floor. The atrium's mean wind speed in each working condition is: test 3 $(1.36 \mathrm{~m} / \mathrm{s})>$ test $1(0.95 \mathrm{~m} / \mathrm{s})>$ test $2(0.79 \mathrm{~m} / \mathrm{s}) \approx$ test 4 $(0.78 \mathrm{~m} / \mathrm{s})$.

On the whole, the area with high wind speed is at lower air temperature, and the atrium's wind speed is negatively correlated with the air temperature. As the temperature of airflow outside the building is lower than that inside the atrium, the airflow into the atrium can take away the heat and play a role in reducing the temperature. The atrium's mean temperature in each working condition is: test $3\left(30.58{ }^{\circ} \mathrm{C}\right)<$ test $1\left(30.79{ }^{\circ} \mathrm{C}\right)<$ test 4 $\left(30.84{ }^{\circ} \mathrm{C}\right)<$ test $2\left(30.98{ }^{\circ} \mathrm{C}\right)$.

\subsubsection{Analysis of PET calculation results}

The sun louver on the top of the atrium of the experimental building model is made of glass, causing ob- vious direct radiation to the interior of the atrium. Because the sun goes west at 14:00, the building itself blocks some direct sunlight in the west direction. Each floor of the atrium forms a gradually expanding heating zone caused by direct radiation from bottom to top, which expands from the east of the first floor to the almost whole floor of the sixth floor. PET of the heating area is obviously higher than that of the surrounding area without direct sunlight, which indicates that direct sunlight has great influence on PET. The atrium's mean PET in each height section increases with the height (except for the sixth floor, of which PET decreases slightly). The atrium's mean PET in each working condition is: test 3 $\left(33.34{ }^{\circ} \mathrm{C}\right)<$ test $1\left(34.29^{\circ} \mathrm{C}\right)<$ test $4\left(34.78^{\circ} \mathrm{C}\right) \approx$ test 2 $\left(34.81^{\circ} \mathrm{C}\right)$.

\section{Conclusion}

This article, taking the office building of Guangzhou Zhujiang Power Plant as the prototype, carries out simulation and analysis of the wind, heat environment and PET of four working conditions. It is concluded that it is beneficial to increase the atrium's mean wind speed, reduce air temperature and PET, and improve comfort index of human body by forming a complete ventilation path inside the building. The ventilation efficiency of air inlet from the side and outlet from the roof is higher than that of air inlet and outlet from the side (L-shaped ventilation path is better than Z-shaped one). Increasing the air inlet is conducive to improving ventilation efficiency and human comfort. It is also concluded that if the air inlet and outlet are located on the same floor of the building, the flow field will not be formed in the atrium, and the short-distance "through wind" will significantly reduce the ventilation effect of the whole atrium and reduce the human comfort.

The experimental results prove that the application of traditional bamboo houses' ventilation principle in modern high-rise buildings can achieve significant benefits. Moreover, the optimization of the combination mode of atrium and side yard in high-rise buildings can further expand the benefits. 

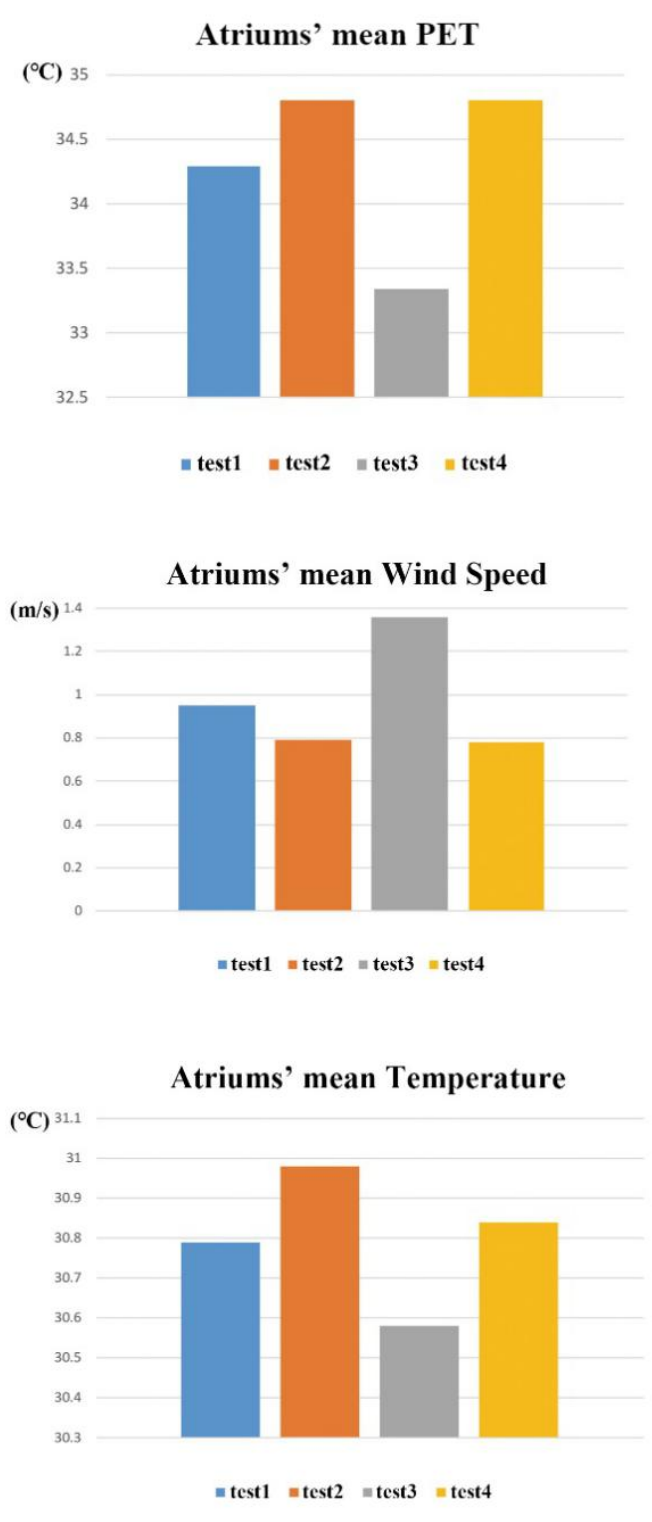

\section{Atriums' mean PET in each height section}

$\left({ }^{\circ} \mathrm{C}\right){ }^{42}$

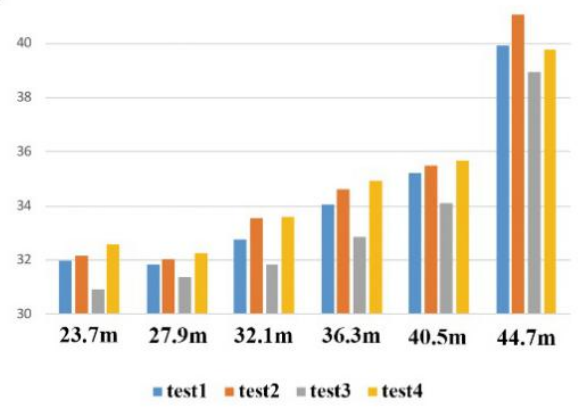

Atriums' mean Wind Speed in each height section $(\mathrm{m} / \mathbf{s})^{2}$

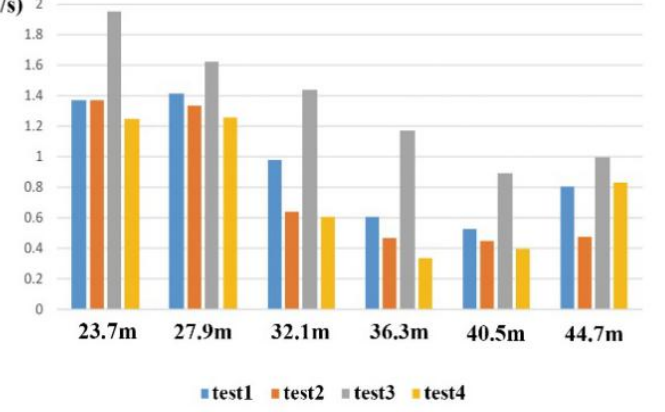

Atriums' mean Temperature in each height section $\left({ }^{\circ} \mathrm{C}\right)^{31 .}$

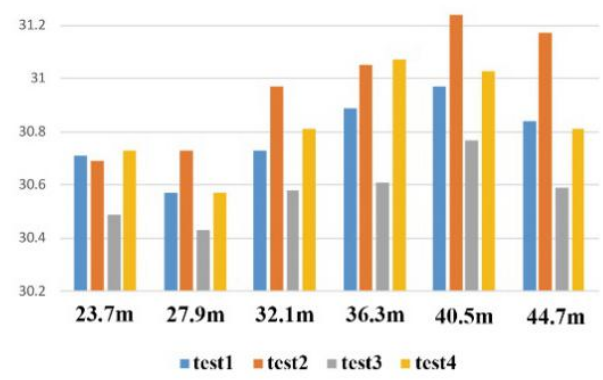

Figure 2. Collection of simulation results. (Source: drawn by the authors)

\section{References}

1. Lu Y. Humanities, character and architecture of Lingnan (in Chinese). Beijing: China Architecture \& Building Press; 2015.

2. Zeng Z. Ventilation method of traditional dwellings in Guangfu and its application in modern architecture [PhD thesis]. Guangzhou: South China University of Technology; 2010.

3. Zeng Z, Lu Q. Significance of the yard for the thermal environment of modern low-rise housing in Lingnan. Architecture Journal 2010; (3): 27-29.
4. Thorsson S, Lindberg F, Eliasson I, et al. Different methods for estimating the mean radiant temperature in an outdoor urban setting. International Journal of Climatology 2007; 27: 1983-1993.

5. Lin TP, Matzarakis A. Tourism climate and thermal comfort in Sun Moon Lake, Taiwan. International Journal of Biometeorology 2008; 52: 281-290.

6. Song Y. Intensifying natural ventilation by use of heat pressure-A case study on the ventilation calculation of the ecological farmhouse in Zhangjiagang City. Architecture Journal 2000; (12): 1214. 